\title{
Different expression patterns of organic anion transporting polypeptides in osteosarcomas, bone metastases and aneurysmal bone cysts
}

\author{
RICHARD LIEDAUER $^{1}$, MARTIN SVOBODA $^{1}$, KATRIN WLCEK $^{4}$, FERDI ARRICH ${ }^{2}$, \\ WALTER JÄGER $^{4}$, CYRIL TOMA $^{2,3}$ and THERESIA THALHAMMER ${ }^{1}$ \\ ${ }^{1}$ Department of Pathophysiology, Center for Physiology and Pathophysiology; ${ }^{2}$ Department of Orthopaedic Surgery, \\ Medical University of Vienna, Vienna, Austria; ${ }^{3}$ Prince Court Medical Centre, Kuala Lumpur, Malaysia; \\ ${ }^{4}$ Department of Clinical Pharmacy and Diagnostics, University of Vienna, Vienna, Austria
}

Received June 5, 2009; Accepted July 16, 2009

DOI: 10.3892/or_00000591

\begin{abstract}
Organic anion transporting polypeptides (OATP) were identified as transmembrane transporters for various endo- and exogenous organic compounds (hormones, prostaglandins, anticancer drugs). OATP expression had been shown in different tissues, but not in bone tumors. Therefore, the expression pattern of all known eleven human OATPs was analyzed by quantitative RT-PCR in 21 human bone tumor specimens (osteosarcomas, bone metastases and benign aneurysmal bone cysts). Transcriptional expression of OATP1A2, 1C1, 2A1, 2B1, 3A1, 4A1, 4C1 and 5A1, but not of OATP1B1, 1B3 and 6A1 was observed in malignant and non-malignant tumor specimens at varying level. Importantly, OATP3A1, 4A1, 2B1 and 1C1 mRNA levels were significantly higher in aneurysmal bone cysts as compared to osteosarcomas. Elevated mRNA levels of OATP2A1, 1A2, and 4C1 in metastases from kidney cancer and of OATP5A1 in prostate cancer suggest that the OATP expression pattern in metastases is comparable to that of the primary tumors. Different to tissue, OATP expression in osteosarcoma cell lines HOS and MG-63, normal human osteoblast outgrowth cells (hOB) and bone marrow stromal cells (BMSC) is limited to OATP3A1 and OATP4A1. High OATP expression levels, particularly in benign bone tumors, suggest an important role of these transporters for providing hormones, their conjugates, prostaglandins and drugs in bone cells. Thereby, they may influence bone resorption and formation.
\end{abstract}

Correspondence to: Dr Theresia Thalhammer, Department of Pathophysiology, Center for Physiology, Pathophysiology and Immunology, Medical University of Vienna, Währinger Gürtel 18-20, A-1090 Vienna, Austria

E-mail: theresia.thalhammer@meduniwien.ac.at

Key words: organic anion transporting polypeptide, drug uptake, bone tumor, multidrug-resistance

\section{Introduction}

Osteosarcomas arising from osteoblasts are among the most frequent solid tumors in teenage cancer patients and in young adults. Surgical resection of lesions combined with radiotherapy, neoadjuvant and adjuvant chemotherapy greatly improved the prognosis of these malignant tumors, particularly, if diagnosis is made at an early stage. Current chemotherapy regimens for all stages include standard anticancer drugs, e.g. methotrexate and doxorubicin in combination with other anticancer drugs (1). In young adults, osteosarcomas, but also benign tumors, e.g. the cartilage-derived chondroma, are often associated with the formation of osteolytic aneurysmal bone cysts, caused by hemodynamic disturbances, post-traumatic events, and reactive vascular malformation. However, aneurysmal bone cysts are also found as primary tumors with a genetical predisposition (2). In older adults, the most common malignant bone tumors are bone metastases derived from primary solid tumors in prostate, breast, kidney and lung. For these bone malignancies, the standard therapy regimen is based on the systemic chemotherapy for the primary tumor (3).

Despite recent progress in the treatment of bone malignancies, the success of a given therapy with respect to an improvement in the quality of life and overall survival, is still hampered by intrinsic or acquired resistance of bone tumor cells to a broad number of anticancer drugs (multidrug resistance, MDR) $(4,5)$. A well established mechanism for MDR is overexpression of efflux transporters such as ABCB1 (P-glycoprotein, Pgp), which can be induced by activation of the chemosensitizing pregnane $\mathrm{X}$ receptor (PXR) through many drugs and xenobiotics. In tumor cells, an enhanced efflux of Pgp substrates such as doxorubicin causes an insufficient intracellular drug accumulation leading to a reduced cytotoxic effect (6). While induction of MDR by ABC-efflux pumps is thoroughly studied, less is known about transporters for the uptake of anticancer drugs into the cells, which may determine net intracellular accumulation and efficacy of drugs $(7,8)$.

In the last decade, it has also became clear that intracellular accumulation of many hormones, prostaglandins and drugs is not simply due to passive diffusion, but evidence is growing that carriers are needed for drug accumulation in certain tissues 
(9). Indeed, members of the organic anion transporting polypeptide (OATP) family encoded by the SLCO genes were identified as sodium-independent transport proteins for various amphipathic organic compounds such as hormones and their conjugates, prostaglandins and others, recently shown to be important in the regulation of bone homeostasis (10). Also xenobiotics including the anticancer drug methotrexate are OATP substrates.

Eleven OATP family members have been identified in humans (11). Some of these OATPs are highly expressed in excretory organs, e.g. liver, kidney, intestine, but others are found at elevated levels in brain, placenta and testes as well as in malignant tissues and cancer cell lines. For example, OATP1A2, known for its wide substrate specificity, is highly expressed in excretory organs, while elevated levels of OATP1C1, a high-affinity thyroid hormone transporter, are found in brain, testes and kidney (12). The prostaglandin transporter OATP2A1 (13) and OATP2B1, transporting steroid hormones such as dehydroepiandrosterone-sulfate (DHEAS) are expressed in a wide number of tissues (14). Ubiquitous tissue distribution was also shown for OATP3A1 and 4A1, for which hormones, drugs and prostaglandins were identified as substrates $(15,16)$. A more restrictive localization was shown for OATP4C1, a kidney-specific transporter for endobiotics and drugs and for two OATPs, OATP6A1 and 5A1, less characterized for their substrate specificity. OATP6A1 was detected in normal testes, some cancer cell lines and malignant tissues, e.g. oesophagus (17-19), and, only recently in our lab (20), OATP5A1 in breast tumors and breast cancer cell lines.

Often an altered OATP expression pattern is seen in malignant tissues and tumor cells as compared to normal tissue (11). For example, OATP1B1 and OATP1B3 were first regarded as liver-specific $(7,8,21)$ but were later also found in intestinal tumors (22) and breast cancer tissues (20).

The wide tissue distribution of various OATPs in normal and malignant tumor cells suggests that OATPs may also be expressed in bone tumors. In bone cells, their activity could influence the local concentration of e.g. estrogen-conjugates, thyroid hormones and prostaglandin E2 (PGE2), which had been shown to regulate bone resorption and formation (osteolytic and osteoblastic processes) (23-25).

Based on these considerations, we investigated mRNA expression of all eleven OATPs in specimens from human osteosarcoma and compared it to that in bone metastases and benign bone tumors by quantitative TaqMan ${ }^{\circledR}$ RT-PCR. We also assessed whether two osteosarcoma cell lines (HOS and MG-63), normal human osteoblast outgrowth cells (hOB) and bone marrow stromal cells (BMSC) might offer suitable models for further investigations on these transporters in bone cells.

\section{Materials and methods}

Samples from bone tumor patients. Patient characteristics are given in Table I. In total, 21 samples from malignant (seven grade 3 osteosarcomas and seven bone metastases from prostate, breast, kidney and lung) and non-malignant bone tumors (six aneurysmal bone cysts and a chondroma, underlying an aneurysmal bone cyst) were analyzed. OATP mRNA expression data for the latter specimen was not incorporated into statistical analysis of OATP mRNA expression in bone tumor groups.

All human tissue samples were obtained during routine surgery at the Department of Orthopaedic Surgery, Medical University of Vienna. Informed consent from all patients was obtained and the study was approved by the Ethics Committee of the institution. Pathological inspection was done by the Department of Clinical Pathology, Medical University of Vienna, Austria.

Cell lines. Two human osteosarcoma cell lines, derived from a female (HOS, ATCC CRL 1543) and a male (MG-63, ATCC CRL 1427) teenage osteosarcoma patient were chosen. These cell lines were originally derived from the American Tissue Culture Collection (ATCC, Manassas, VA). Cells were routinely cultured in RPMI-1640 medium supplemented with $10 \%$ FCS and $1 \%$ penicillin/streptomycin under standard culture conditions.

Human osteoblast outgrowth cells (hOB) were isolated from human cancellous bone obtained during orthopaedic surgery (hip replacement); bone marrow derived stromal cells (BMSC) were isolated from an aspirate of human bone marrow, derived from the superior iliac crest of the pelvis. Both bone cell types were regarded normal and cultured, as described previously (26).

Expression analysis. Total RNA was isolated from 21 frozen tissue samples, cancer cell lines grown to subconfluency and cultured hOB and BMSC cells using the TRIzol reagent (Invitrogen Life Technologies, Paisley, Scotland). One microgram of total RNA per sample was reverse transcribed to cDNA using the RevertAid ${ }^{\mathrm{TM}} \mathrm{H}$ Minus M-MuLV Reverse Transcriptase (Fermentas Life Sciences, Vilnius, Lithuania). The purity of extracted RNA was assessed by determination of the $\mathrm{A}_{260} / \mathrm{A}_{280}$ ratio and by separation on a $2 \%$ agarose gel. To quantify the expression of SLCO/OATP, Pgp and PXR mRNA, multiplex realtime (RT)-PCR, using TaqMan gene expression assays (Applied Biosystems, Foster City, CA) was performed, as described previously (20). Following TaqMan assays were used: Hs00245360_m1 (OATP1A2), Hs00272 374_m1 (OATP1B1), Hs00251986_m1 (OATP1B3), Hs00213714_m1 (OATP1C1), Hs00194554_m1 (OATP2A1), HS00200670_m1 (OATP2B1), Hs00203184_m1 (OATP3A1), Hs00249583_m1 (OATP4A1), Hs00698884_m1 (OATP4C1), Hs00229597_m1 (OATP5A1), Hs00542846_m1 (OATP6A1), Hs00184500_m1 (Pgp), Hs00243666_m1 (PXR). All samples were tested in triplicates, using an ABI PRISM 7700 Sequence Detection System (Applied Biosystems). Thermal cycling conditions comprised $2 \mathrm{~min}$ at $50^{\circ} \mathrm{C}, 10 \mathrm{~min} 95^{\circ} \mathrm{C}$ followed by 40 cycles of $15 \mathrm{sec}$ at $95^{\circ} \mathrm{C}$ and $1 \mathrm{~min}$ at $60^{\circ} \mathrm{C}$. Sequence Detection Software (SDS 1.9.1, Applied Biosystems) results were imported into the software Q-gene for further processing and calculation of mean normalized expression (MNE) levels according to the equation: $\mathrm{MNE}=$ $\left.\left.\left(\mathrm{E}_{\text {reference }}\right)^{\wedge} \mathrm{C} \mathrm{T}_{\text {reference, mean }}\right) /\left(\mathrm{E}_{\text {target }}\right)^{\wedge} \mathrm{C} \mathrm{T}_{\text {target, mean }}\right)$, where $\mathrm{E}_{\text {target }}$ and $\mathrm{E}_{\text {reference }}=$ efficiency of PCR amplification of the target and the reference, respectively; $\mathrm{CT}_{\text {target, mean }}$ and $\mathrm{CT}_{\text {reference, mean }}$ are calculated means for the target and the reference, respectively (27). RT-data were normalized to the most stably expressed housekeeping gene, cytochrome $\mathrm{C}-1$ (CYC1), identified using 
Table I. Characteristics of tumor patients and tumors. ${ }^{a}$

\begin{tabular}{|c|c|c|c|c|c|}
\hline Osteosarcomas & $\#$ & Type & Age & Gender & Location \\
\hline & 1 & Osteoblastic & 16 & M & Distal femur (r) \\
\hline & 2 & Osteoblastic/anablastic & 15 & M & Proximal humerus (1) \\
\hline & 3 & Osteoblastic/chondroblastic & 16 & M & Proximal tibia (r) \\
\hline & 4 & Osteoblastoma-like & 34 & $\mathrm{~F}$ & Proximal femur (r) \\
\hline & 5 & Chondroblastic & 53 & $\mathrm{~F}$ & Distal femur (r) \\
\hline & 6 & Osteoblastic & 15 & $\mathrm{~F}$ & Proximal humerus (r) \\
\hline & 7 & Parosteal & 36 & $\mathrm{~F}$ & Distal femur (r) \\
\hline \multirow[t]{8}{*}{ Metastases } & $\#$ & Primary tumor & Age & Gender & Location \\
\hline & 8 & Prostate & 83 & M & Femoral head \\
\hline & 9 & Prostate & 74 & M & Humerus (r) \\
\hline & 10 & Mamma & 36 & $\mathrm{~F}$ & Femoral neck \\
\hline & 11 & Mamma & 65 & $\mathrm{~F}$ & Femur (l) \\
\hline & 12 & Kidney & 54 & M & Femoral head \\
\hline & 13 & Kidney & 65 & M & Femoral head \\
\hline & 14 & Lung & 58 & M & Os ilium \\
\hline \multirow[t]{8}{*}{ Benign tumors } & $\#$ & Type of lesion & Age & Gender & Location \\
\hline & 15 & Aneurysmal bone cyst & N/A & $\mathrm{F}$ & N/A \\
\hline & 16 & Aneurysmal bone cyst & 11 & M & Humerus (l) \\
\hline & 17 & Aneurysmal bone cyst & 12 & $\mathrm{~F}$ & Os ilium (1) \\
\hline & 18 & Aneurysmal bone cyst & 19 & M & Acetabulum \\
\hline & 19 & Aneurysmal bone cyst & 58 & M & Femoral neck \\
\hline & 20 & Aneurysmal bone cyst & 17 & M & Femur (l) \\
\hline & 21 & Ahondroma & 19 & M & Os sacrum \\
\hline
\end{tabular}

${ }^{a}$ All osteosarcoma specimens were derived from histological grade (G) 3 tumors. All osteosarcoma patients received neoadjuvant chemotherapy according to the COSS regimen (33).

the geNorm ${ }^{\mathrm{TM}}$ housekeeping gene selection kit (PrimerDesign Ltd.). The following intron-spanning primers and the TaqMan probe for CYC1 were designed using the software Primer Express $^{\mathrm{TM}}$ V1.5 (Applied Biosystems): CYC1-f. p.: 5'-GTT TGA CGA TGG CAC CCC AG-3'; r. p.: 5'-CTT GAG CCC CAT GCG TTT T-3'; TaqMan probe: Tamra-5'-CCC AGA TAG CCA AGG ATG TGT GCA CCT-3'-Blackhole quencher 2 .

Data analysis. RT-PCR data were statistically analyzed by one-way ANOVA; P-values of $\leq 0.05$ were considered statistically significant.

\section{Results}

Transcriptional expression of OATPs in human bone tumor specimens. Quantitative RT-PCR was used to determine the mRNA expression pattern of all eleven OATPs in samples from malignant and non-malignant bone tumors. As demonstrated in Fig. 1, eight OATPs, namely OATP1A2, 1C1, 2A1, 2B1, 3A1, 4A1, 4C1 and 5A1 were detected in a collective of 21 bone tumor specimens, consisting of seven poorly differentiated osteosarcomas (specimens \#1-7), seven bone metastases (specimens \#8-14) from solid tumors in the prostate, breast, kidney $(\mathrm{n}=2$, each) and lung $(\mathrm{n}=1)$ and seven specimens from benign bone lesions (specimens \#15-21). Data for individual patients are given in Table I: Eight specimens were from female, 13 from male patients with a female to male ration of $4 / 3$ in osteosarcoma, 2/5 in metastases and 2/5 benign bone tumors, respectively. Osteosarcoma and benign bone tumor patients were of similar age: mean age: $26.4 \pm 14.9$ and $22.7 \pm 17.6$ years, respectively, while patients in the metastatic tumor group were older: mean age $62.1 \pm 15.0$ years $(\mathrm{P} \leq 0.05)$.

In all tumor samples, mRNA expression of three transporters, OATP1C1, 2A1 and 4A1, was present at a considerable level. For two other transporters, namely OATP2B1 and OATP3A1, mRNA expression was found in all but one sample. While OATP2B1 was undetectable in a prostate cancer metastasis (\#8), OATP3A1 mRNA levels were below the detection limit in a metastasis from breast cancer (\#11).

As demonstrated in Fig. 1A and Table II, mean OATP mRNA expression levels of four transporters (OATP1C1, 2B1, $3 \mathrm{~A} 1$, and 4A1) were 2-3-fold higher $(\mathrm{P}<0.001-0.05)$ in the aneurysmal bone cyst group than in the osteosarcoma group. 

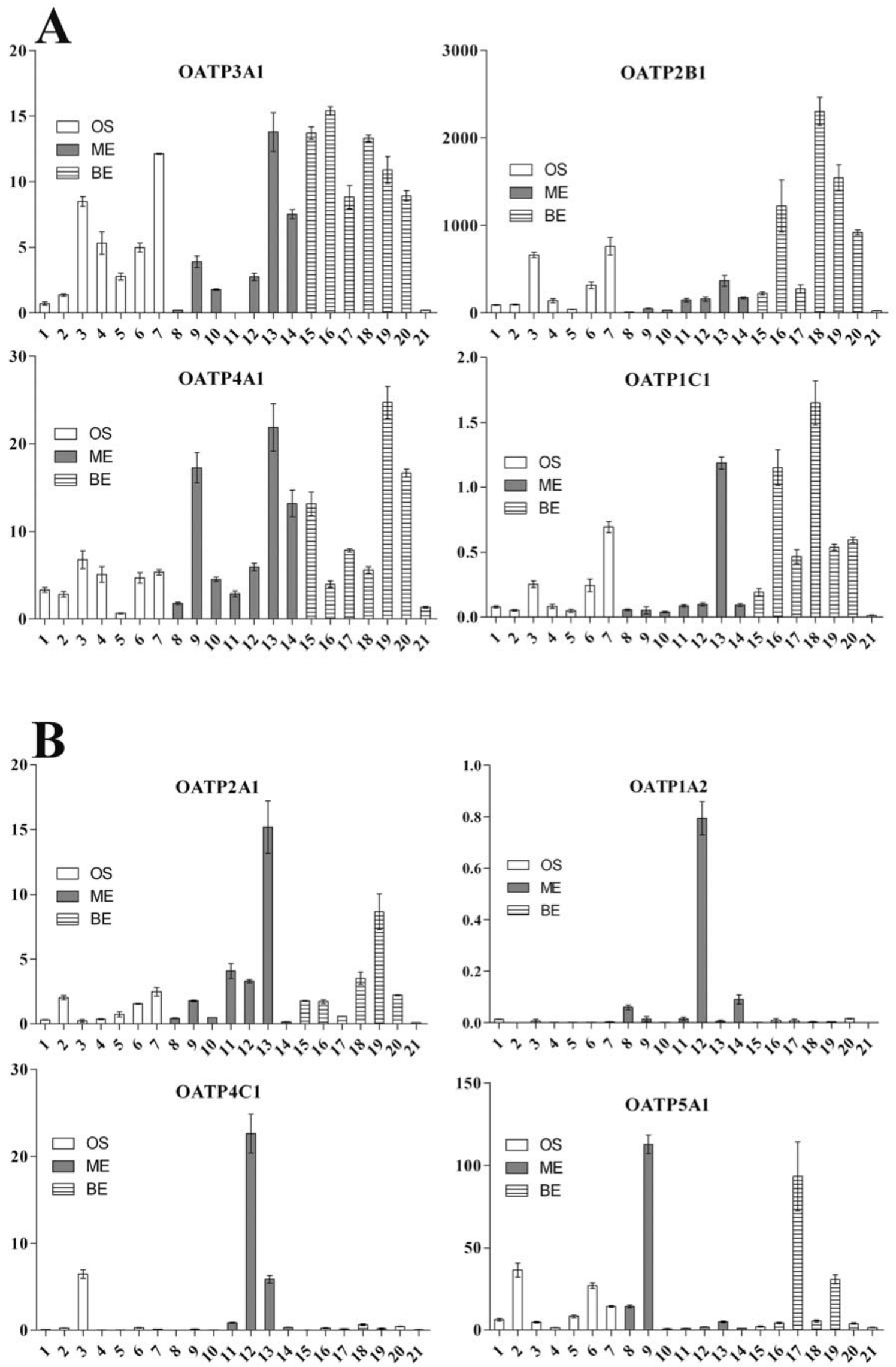

Figure 1. OATP mRNA expression in human bone tumor specimens. mRNA expression of 11 OATPs was assessed in specimens from osteosarcomas (OS; $\# 1-7)$, metastases $(\mathrm{ME})$ from prostate $(\# 8,9)$, breast $(\# 10,11)$, kidney $(\# 12,13)$ and lung $(\# 14)$ tumors and benign bone tumors (BE; aneurysmal bone cyst: \#15-20, chondroma: \#21*); mRNA expression of eight OATPs, namely OATP1A2, 1C1, 2A1, 2B1 (A), 3A1, 4A1, 4C1 and 5A1 (B) was detected, while other OATPS (OATP1B1, 1B3 and 6A1) were below the detection limit in all specimens. Expression levels are given as mean normalized expression (MNE), calculated as described in the Materials and methods section. 
Table II. Mean MNE (mean normalized expression) levels of OATP-, Pgp- and PXR-mRNA (mean \pm SD) in bone tumor specimens.

\begin{tabular}{|c|c|c|c|}
\hline & Osteosarcoma & Bone metastases & Aneurysmal bone cysts \\
\hline OATP1A2 & $0.004 \pm 0.005$ & $0.14 \pm 0.29$ & $0.006 \pm 0.006$ \\
\hline OATP1C1 & $0.21 \pm 0.23^{\mathrm{a}}$ & $0.23 \pm 0.42$ & $0.66 \pm 0.57$ \\
\hline OATP2A1 & $1.10 \pm 0.92$ & $3.63 \pm 5.31$ & $2.65 \pm 2.87$ \\
\hline OATP2B1 & $300.9 \pm 295.1^{\mathrm{a}}$ & $134.29 \pm 122.99^{b}$ & $929.8 \pm 825.9$ \\
\hline OATP3A1 & $5.11 \pm 4.1^{b}$ & $4.28 \pm 4.90^{b}$ & $10.18 \pm 5.04$ \\
\hline OATP4A1 & $4.07 \pm 2.01^{\mathrm{a}}$ & $9.63 \pm 7.83$ & $10.46 \pm 8.22$ \\
\hline OATP4C1 & $1.04 \pm 2.40$ & $4.27 \pm 8.37$ & $0.25 \pm 0.22$ \\
\hline OATP5A1 & $14.11 \pm 12.97$ & $19.55 \pm 41.41$ & $20.23 \pm 33.86$ \\
\hline Pgp & $3.93 \pm 3.87$ & $3.50 \pm 6.82$ & $3.14 \pm 2.68$ \\
\hline PXR & $1.36 \pm 0.92$ & $0.92 \pm 0.71$ & $1.01 \pm 0.63$ \\
\hline
\end{tabular}

mRNA expression of different OATPs, Pgp and PXR was analyzed using TaqMan ${ }^{\circledR}$ gene expression assays as described in the Materials and methods section. Mean normalized expression levels were calculated using the software Q-gene; statistically significant differences were calculated by one-way ANOVA: ${ }^{\mathrm{a}} \mathrm{P}<0.05$ vs. bone cysts group; ${ }^{\mathrm{b}} \mathrm{P}<0.01 \mathrm{vs}$. bone cysts group. Bold, significantly higher expression levels in benign vs. malignant tumors.

For OATP2B1 and 3A1 mRNA expression levels, significant differences $(\mathrm{P}<0.001)$ were additionally found between aneurysmal bone cysts and the metastatic bone tumor group. Up to 6-fold higher levels were seen for OATP2B 1 in aneurysmal bone cysts as compared to metastases, while for OATP3A1 differences were 2-fold.

Generally, OATP mRNA expression levels, given as mean normalized expression (MNE), varied in individual patients (Fig. 1A and B). Only for OATP3A1 and 4A1 mRNA expression, a more uniform pattern was observed. Similar levels with an up to 20- and 30-fold enrichment were observed in individual samples, particularly in the benign bone cyst group. Highest mRNA expression levels of all OATPs detected in bone tumors were seen for OATP2B1 which showed a maximal enrichment of 2.5-fold in an aneurysmal bone cysts (\#18). OATP1C1 mRNA expression levels were generally low and reached a maximal enrichment of only 1.8-fold, also found in sample \#18. Despite the enormous differences in the expression levels, the MNE pattern for these two OATPs were similar in individual specimens from malignant and benign primary bone tumors.

As indicated in Fig. 1B and Table II, for OATP2A1, mean mRNA expression levels were higher in some aneurysmal bone cyst and metastases samples, but mean MNEs did not differ significantly between the groups. Highest (16-fold) expression was found in the kidney metastasis (\#13). For three other transporters, OATP1A2, 4C1 and OATP5A1, mRNA expression levels were particularly high in kidney (OATP1A2 and 4C1 in specimens \#12 with a 0.8 -fold and 22-fold enrichment) and prostate (OATP5A1 in specimen \#9 with a 110-fold enrichment) metastases. While OATP4C1 mRNA was detected only in one of the osteosarcoma specimens (\#3), OATP5A1 mRNA was additionally found in a number of aneurysmal bone cysts and osteosarcoma specimens.

For three other OATPs, namely OATP 1B1, 1B3 and 6A1, mRNA expression levels were below the detection limit in all bone tumor specimens and cells investigated.
OATP expression in osteosarcoma cell lines and in normal $h O B$ and BMSC. To compare the OATP expression pattern in malignant bone tumor samples with that in isolated bone cells, we studied OATP mRNA expression in malignant MG-63 and HOS osteosarcoma cell lines, originating from a male and a female patient. As a model for normal bone cells, we used normal human osteoblast outgrowth cells (hOB) and did additional studies in bone marrow stromal cells (BMSC).

As shown in Fig. 2, mRNA expression of only three OATPs, namely OATP1A2, 3A1 and 4A1, was detected in the HOS and MG-63 cells at MNE levels similar to that in the bone tumors. OATP1A2 and 4A1 mRNA expression were even higher ( 1.4- and 1.7-fold) in MG-63 cells than in HOS cells.

In hOB and BMSC, only OATP3A 1 and OATP4A1 mRNA were expressed at similar levels in both cell types. However, in hOB and BMSC cells, OATP3A1 levels were 5-6 times higher than in the osteosarcoma cell lines. In contrast to bone tumors, OATP4A1 mRNA expression levels were 5-6 times lower in normal cells as compared to the osteosarcoma cell lines.

Expression of Pgp and PXR mRNA in bone tumors and bone cells. We also assessed whether mRNA expression of ABCB1 coding for the MDR efflux pump Pgp, and for the nuclear receptor PXR, might be correlated with a specific OATP pattern in malignant and non-malignant bone tumors and in bone cell lines.

As demonstrated in Fig. 3, Pgp mRNA expression was detected in all osteosarcoma specimens, bone metastases and benign bone tumors. As shown in Table II, mean MNEs were similar in aneurysmal bone cysts as compared to metastases and osteosarcomas. Highest Pgp mRNA expression levels were found in a renal cancer metastasis (\#12) and in an osteosarcoma (\#1) specimen (MNEs: 18- and 11-fold, respectively). On the other hand, Pgp mRNA expression was near the detection limit in the metastases from prostate (\#8) and breast (\#10) cancer as well as in the chondroma (\#21) specimen. 

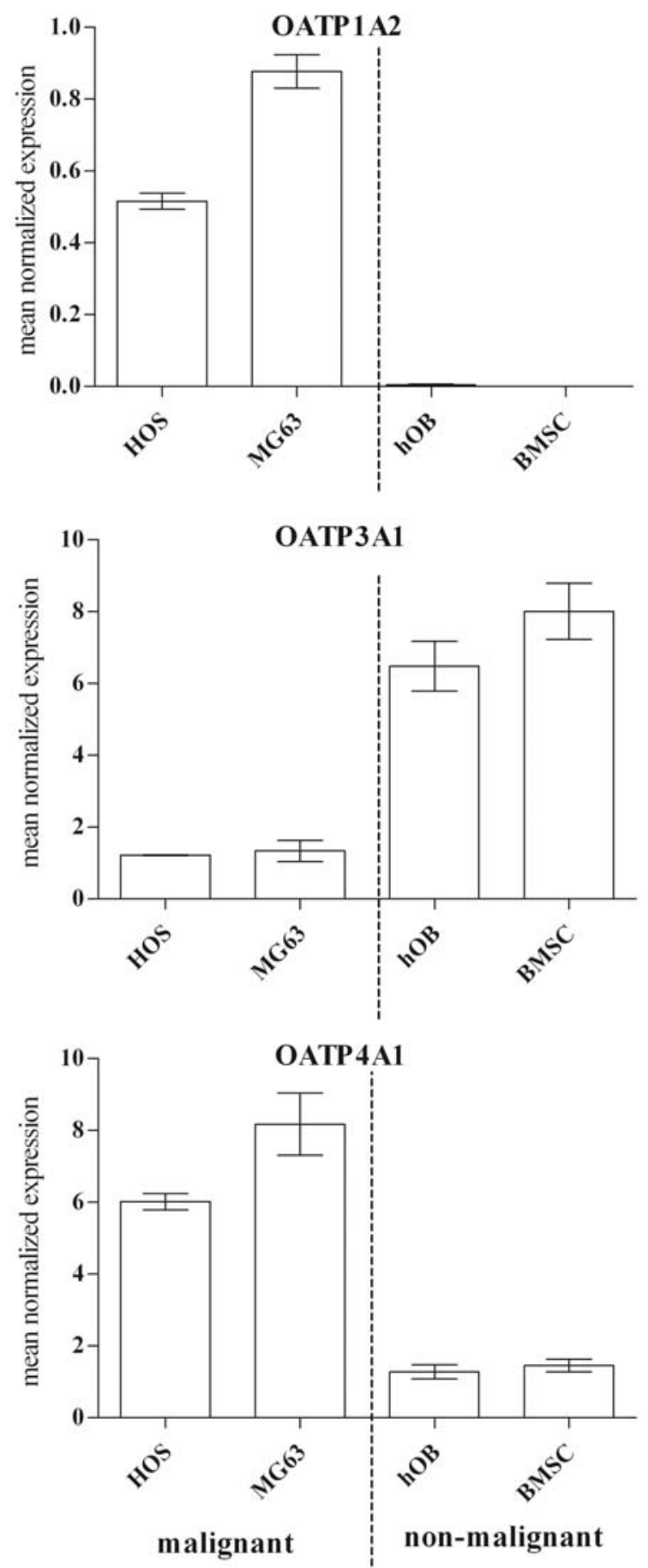

Figure 2. OATP mRNA expression in malignant and non-malignant bone cells. mRNA expression of 11 OATPs was assessed in the osteosarcoma cell lines HOS and MG-63 and in the normal human bone marrow derived osteoblastoutgrowth cells (hOB) and bone marrow stromal cells (BMSC) by quantitative PCR; mRNA expression of three OATPs, namely OATP1A2, 3A1 and 4A1 was detected, while other OATPs (OATP1B1, 1B3, 1C1,2A1, 2B1, 4C1, 5A1 and 6A1) were below the detection limit in all cell lines and bone cells.

Contrary to bone tumor specimens, Pgp mRNA expression levels were below the detection limit in osteosarcoma cell lines, hOB and BMSC.

Similarly to Pgp, PXR mRNA expression levels did not differ between the bone tumor groups. Maximal enrichment of PXR mRNA in individual samples was lower than that of Pgp. Up to 2.8-fold higher PXR mRNA levels were found in two
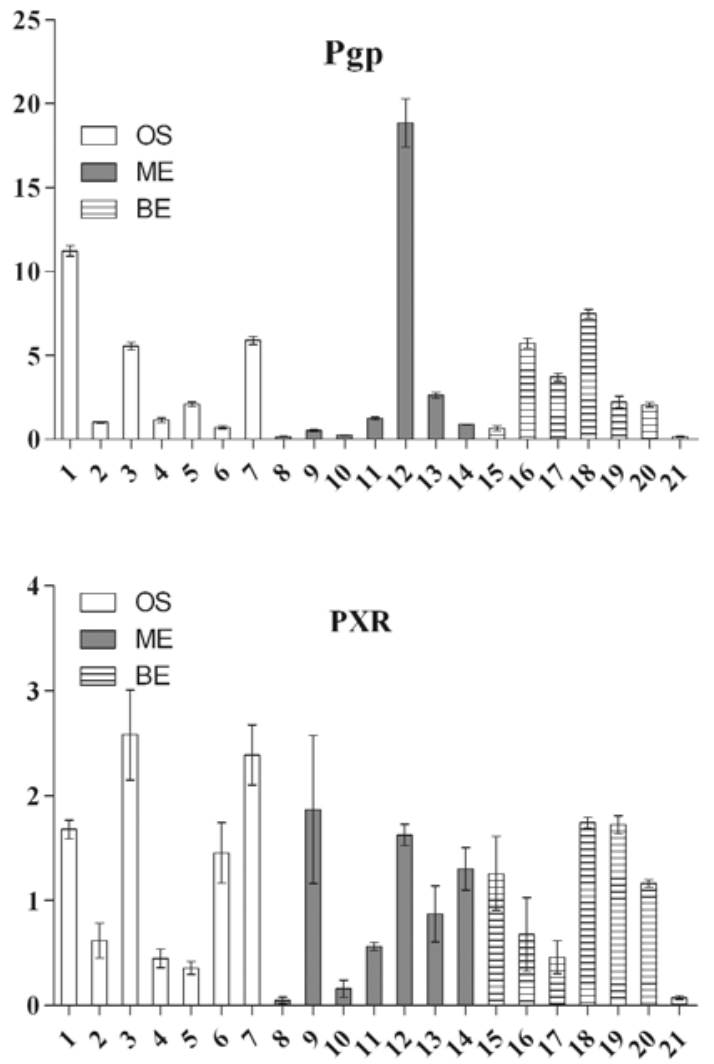

Figure 3. Pgp and PXR mRNA expression in human bone tumor specimens. mRNA expression of the MDR efflux pump P-glycoprotein (Pgp) and the nuclear receptor PXR was assessed in specimens from osteosarcomas (OS; $\# 1-7)$, metastases (ME) from prostate $(\# 8,9)$, breast $(\# 10,11)$, kidney $(\# 12,13)$ and lung (\#14) tumors and benign bone tumors (BE; aneurysmal bone cyst: \#15-20, chondroma: \#21*). Pgp mRNA was detected in all specimens, with highest expression levels in a metastasis from renal cancer (\#12) and an osteosarcoma specimen (\#1).

osteosarcoma specimens, one from a responder to chemotherapy (\#3) and one from a non-responder (specimen \#7).

In the two osteosarcoma cell lines, however, PXR mRNA expression was also near the detection level, while that in normal hOB and BMSC were similar to that in bone tumors ( 0.9-fold).

\section{Discussion}

This is the first demonstration of transcriptional expression of eight of eleven known human OATPs, namely OATP1A2, $1 \mathrm{C} 1,2 \mathrm{~A} 1,2 \mathrm{~B} 1,3 \mathrm{~A} 1,4 \mathrm{~A} 1,4 \mathrm{C} 1$ and $5 \mathrm{~A} 1$, in human bone tumors. Most widely expressed were OATP $3 \mathrm{~A} 1$ and 4A1, which were found at considerable levels in nearly all bone tumor specimens, HOS and MG-36 osteosarcoma cell lines, normal hOB cells and BMSCs. Osteosarcoma cell lines (MG-63 and HOS) and normal bone-derived cells (hOB and BMSC) are therefore not suitable models for studying OATPmediated transport processes as OATP expression levels were considerably lower compared to bone tumor samples.

We found differences in the expression pattern between non-malignant and malignant bone tumors, as mRNA expression levels of OATP3A1, 4A1, 2B1 and $1 \mathrm{C} 1$ were significantly higher in the bone cyst group than in the osteo- 
sarcoma group. This is in accordance with previous data from our lab (20), showing that OATP3A1, 4A1 and 2B1 are higher expressed in benign vs. malignant breast tissue. Ancona et al (28) also found higher OATP4A1 levels in normal vs. malignant colon suggesting that OATP3A1, 4A1, 2B1 and possibly, also $1 \mathrm{C} 1$ may play an important role in providing endogenous OATP substrates e.g. hormones to cells. For example, thyroid hormones are substrates for many OATPs, e.g. OATP3A1, 4A1, and OATP1C1 (12), which have the highest affinity for these hormones. We found high levels of OATP1C1 in osteolytic aneurysmal bone cysts and kidney metastases, which would fit with the bone resorptive effect of thyroid hormones (29). On the other hand, this OATP was also highly expressed in the osteoblastic prostate metastases.

Another important substrate is estrone-sulfate, which is present at high levels in plasma. It could be taken up into bone cells by OATP2B1 and other OATPs, e.g. 3A1. In bone cells, it is further metabolized to $17 ß$-estradiol (E2) by estrogenmetabolizing enzymes (26) providing the active estrogen. Furthermore, OATP2B1 also transports DHEAS, which is a precursor for E2. Indeed, E2 derived from DHEAS was found to stimulate bone formation (30).

Prostaglandins, e.g. PGE2, are substrates for many OATPs, e.g. OATP1A3 and 4A1, but OAT2A1, highly expressed in many organs, e.g. brain, colon, kidney, has the highest specificity for these mediators (31). PGE2 is not only important for tumor development, but it is also a potent inducer of osteolysis (25). Although biological effects of PGE2 are mediated by binding to its plasma membrane receptors, transport of PGE2 into the cell by OATP2A1 leads to rapid inactivation by oxidation in the cell interior (13).

Our data show, particular high OATP2A1 levels in an osteolytic kidney metastasis. This seems to reflect the function of OATP2A1 in the primary tumor of the kidney, where its expression is regulated by electrolytes, e.g. high sodium (32).

We further demonstrated in this pilot study that the 'kidneyspecific OATP4C1' (18) is almost exclusively expressed in kidney metastases, however, low levels are also found in prostate and lung metastases. This further suggests that the OATP expression pattern in metastases, at least in that from renal cancer, is comparable to that of the primary tumor. Whether OATPs might be used as biomarkers to define the primary tumor of metastases is not known yet and has to be investigated. In breast cancer metastases, however, OATP expression did not correlate with primary tumor as OATP2B1 and 4A1, considerably expressed in breast cancer tissue (20), were found only at low expression levels in the breast metastases.

In our study, all osteosarcoma patients had received neoadjuvant chemotherapy based on doxorubicin and methotrexate (33). On the other hand, from the OATPs previously found to transport methotrexate (OATP1A2, 1B1, 1B3, 4C1), only OATP 4C1 was expressed at a considerable level in the osteosarcoma specimen \#3, derived from a responder to chemotherapy. This suggests that other not yet identified transporters could also be important for the cellular uptake of methotrexate into osteosarcoma cells. This might also apply for the uptake of doxorubicin.

In addition to the OATP-mediated uptake, net cellular accumulation of drugs and endogenous compounds is determined by their efflux from the cells. So did recent data showing that doxorubicin used for treatment of osteosarcomas could also induce overexpression of ABC-efflux transporters such as ABCB1 (Pgp). Our data, however, could not show any induction of Pgp in samples from doxorubicintreated patients vs. untreated aneurysmal bone cysts patients.

Gender, tumor localization and age do not seem to be related to OATP and Pgp expression. Furthermore, the OATP expression pattern in individual samples did not correlate with Pgp and PXR, although transcriptional regulation of OATP1A2 and 2B1 by PXR activation was previously shown in liver (34).

In summary, our data revealed that 8 out of 11 OATPs (OATP1A2, 1C1, 2A1, 2B1, 3A1, 4A1, 4C1 and 5A1) are expressed in human bone tumors with differences in the expression levels between osteosarcomas, bone metastases and benign bone tumors. The distinct pattern of expression indicates that OATPs could be important to provide important regulators of bone homeostasis and affect tumor growth and progression. Additionally, OATP-mediated uptake of certain anticancer drugs may also influence the efficacy of chemotherapy regimens in which OATP substrates are applied.

\section{Acknowledgements}

Parts of this study were supported by the OVCAD Strep Project (FA751C0203) (T.T., M.S.) and a grant from the Juoiläumsfonds der DENB (P12600, W.I., K.W.).

\section{References}

1. Chou AJ, Geller DS and Gorlick R: Therapy for osteosarcoma: where do we go from here? Paediatr Drugs 10: 315-327, 2008.

2. Cottalorda J and Bourelle S: Modern concepts of primary aneurysmal bone cyst. Arch Orthop Trauma Surg 127: 105-114, 2007.

3. Clines GA and Guise TA: Molecular mechanisms and treatment of bone metastasis. Expert Rev Mol Med 6: e7, 2008.

4. Clark JC, Dass CR and Choong PF: A review of clinical and molecular prognostic factors in osteosarcoma. J Cancer Res Clin Oncol 134: 281-297, 2008.

5. Walters DK, Steinmann P, Langsam B, Schmutz S, Born W and Fuchs B: Identification of potential chemoresistance genes in osteosarcoma. Anticancer Res 28: 673-679, 2008.

6. Zhou SF: Structure, function and regulation of P-glycoprotein and its clinical relevance in drug disposition 38: 802-832, 2008.

7. Hagenbuch B and Meier PJ: Organic anion transporting polypeptides of the OATP/SLC21 family: phylogenetic classification as OATP/SLCO superfamily, new nomenclature and molecular/functional properties. Pflugers Arch 447: 653-665, 2004.

8. Mikkaichi T, Suzuki T, Tanemoto M, Ito S and Abe T: The organic anion transporter (OATP) family. Drug Metab Pharmacokinet 19: 171-179, 2004.

9. Dobson PD and Kell DB: Carrier-mediated cellular uptake of pharmaceutical drugs: an exception or the rule? Nat Rev Drug Discov 7: 205-220, 2008.

10. Gallagher JC: Advances in bone biology and new treatments for bone loss. Maturitas 60: 65-69, 2008.

11. Hagenbuch B and Gui C: Xenobiotic transporters of the human organic anion transporting polypeptides (OATP) family. Xenobiotica 38: 778-801, 2008.

12. Hagenbuch B: Cellular entry of thyroid hormones by organic anion transporting polypeptides. Best Pract Res Clin Endocrinol Metab 21: 209-221, 2007.

13. Nomura T, Lu R, Pucci ML and Schuster VL: The two-step model of prostaglandin signal termination: in vitro reconstitution with the prostaglandin transporter and prostaglandin 15 dehydrogenase. Mol Pharmacol 65: 973-978, 2004. 
14. Grube M, Köck K, Karner S, Reuther S, Ritter CA, Jedlitschky G and Kroemer HK: Modification of OATP2B1-mediated transport by steroid hormones. Mol Pharmacol 70: 1735-1741, 2006.

15. Tamai I, Nezu J, Uchino H, Sai Y, Oku A, Shimane M and Tsuji A: Molecular identification and characterization of novel members of the human organic anion transporter (OATP) family. Biochem Biophys Res Commun 273: 251-260, 2000.

16. Huber RD, Gao B, Sidler Pfändler MA, Zhang-Fu W, Leuthold S, Hagenbuch B, Folkers G, Meier PJ and Stieger B: Characterization of two splice variants of human organic anion transporting polypeptide 3A1 isolated from human brain. Am J Physiol Cell Physiol 292: C795-C806, 2007.

17. Satoh F, Unno M, Nunoki K, Suzuki M, Hishinuma T, Goto J Shimosegawa T, Matsuno S, Ito S and Abe T: Identification and characterization of novel rat and human gonad-specific organic anion transporters. Mol Endocrinol 17: 1203-1215, 2003.

18. Mikkaichi T, Suzuki T, Onogawa T, Tanemoto M, Mizutamari H, Okada M, Chaki T, Masuda S, Tokui T, Eto N, Abe M, Satoh F, Unno M, Hishinuma T, Inui K, Ito S, Goto J and Abe T: Isolation and characterization of a digoxin transporter and its rat homologue expressed in the kidney. Proc Natl Acad Sci USA 101: 3569-3574, 2004.

19. Lee SY, Williamson B, Caballero OL, Chen YT, Scanlan MJ, Ritter G, Jongeneel CV, Simpson AJ and Old LJ: Identification of the gonad-specific anion transporter SLCO6A1 as a cancer/ testis (CT) antigen expressed in human lung cancer. Cancer Immun 4: 13, 2004.

20. Wlcek K, Svoboda M, Thalhammer T, Sellner F, Krupitza G and Jaeger W: Altered expression of organic anion transporter polypeptide (OATP) genes in human breast carcinoma. Cancer Biol Ther 7: 1450-1455, 2008.

21. Smith NF, Figg WD and Sparreboom A: Role of the liver-specific transporters OATP1B1 and OATP1B3 in governing drug elimination. Expert Opin Drug Metab Toxicol 1: 429-445, 2005.

22. Ballestero MR, Monte MJ, Briz O, Jimenez F, Gonzalez-San Martin F and Marin JJ: Expression of transporters potentially involved in the targeting of cytostatic bile acid derivatives to colon cancer and polyps. Biochem Pharmacol 72: 729-738, 2006.

23. Raisz LG: Pathogenesis of osteoporosis: concepts, conflicts, and prospects. J Clin Invest 115: 3318-3325, 2005.

24. Biondi B and Cooper DS: The clinical significance of subclinical thyroid dysfunction. Endocr Rev 29: 76-131, 2008.
25. Hikiji H, Takato T, Shimizu $\mathrm{T}$ and Ishii S: The roles of prostanoids, leukotrienes, and platelet-activating factor in bone metabolism and disease. Prog Lipid Res 47: 107-126, 2008.

26. Svoboda M, Thalhammer T, Aust S, Arrich F, Assadian O and Toma CD: Estrogen sulfotransferase (SULT1E1) expression in benign and malignant human bone tumors. J Surg Oncol 95: 572-581, 2007.

27. Muller PY, Janovjak H, Miserez AR and Dobbie Z: Processing of gene expression data generated by quantitative real-time RT-PCR. Biotechniques 32: 1372-1379.

28. Ancona N, Maglietta R, Piepoli A, D'Addabbo A, Cotugno R, Savino M, Liuni S, Carella M, Pesole G and Perri F: On the statistical assessment of classifiers using DNA microarray data. BMC Bioinformatics 7: 387, 2006.

29. Harvey CB, O'Shea PJ, Scott AJ, Siebler T, Shalet SM, Samarut J, chassande $\mathrm{O}$ and Williams GR: Molecular mechanisms of thyroid hormone effects on bone growth and function. Mol Genet Metab 75: 17-30, 2002.

30. Jankowski CM, Gozansky WS, Kittelson JM, Van Pelt RE, Schwartz RS and Kohrt WM: Increases in bone mineral density in response to oral dehydroepiandrosterone replacement in older adults appear to be mediated by serum estrogens. J Clin Endocrinol Metab 93: 4767-4773, 2008.

31. Schuster VL: Prostaglandin transport. Prostaglandins and other lipid mediated $\mathrm{ABC}$ multidrug transporters: structure, function and role in chemoresistance. Pharmacogenomics 9: 105-127, 2008.

32. Chi Y, Pucci ML and Schuster VL: Dietary salt induces transcription of the prostaglandin transporter gene in renal collecting ducts. Am J Physiol Renal Physiol 295: F765-F771, 2008.

33. Eselgrim M, Grunert H, Kuhne T, Zoubek A, Kevric M, Bürger H, Jürgens H, Mayer-Steinacker R, Gosheger G and Bielack SS: Dose intensity of chemotherapy for osteosarcoma and outcome in the Cooperative Osteosarcoma Study Group (COSS) trials. Pediatr Blood Cancer 47: 42-50, 2006.

34. Gui C, Miao Y, Thompson L, Wahlgren B, Mock M, Stieger B and Hagenbuch B: Effect of pregnane $\mathrm{X}$ receptor ligands on transport mediated by human OATP1B1 and OATP1B3. Eur J Pharmacol 584: 57-65, 2008. 